\title{
A Twin Study of Chronic Fatigue
}

Dedra Buchwald, MD, Richard Herrell, PhD, Suzanne Ashton, BS, Megan Belcourt, BS, Karen Schmaling, PhD, Patrick Sullivan, MD, Michael Neale, PhD, and Jack Goldberg, PhD

Objective: The etiology of chronic fatigue syndrome is unknown, but genetic influences may be important in its expression. Our objective was to assess the role of genetic and environmental factors in unexplained chronic fatigue. Methods: A classic twin study was conducted using 146 female-female twin pairs, of whom at least one member reported $\geq 6$ months of fatigue. After completing questionnaires on symptoms, zygosity, physical health, and a psychiatric interview, twins were classified using three increasingly stringent definitions: 1) chronic fatigue for $\geq 6$ months, 2) chronic fatigue not explained by exclusionary medical conditions, and 3) idiopathic chronic fatigue not explained by medical or psychiatric exclusionary criteria of the chronic fatigue syndrome case definition. Concordance rates in monozygotic and dizygotic twins were calculated for each fatigue definition along with estimates of the relative magnitude of genetic and environmental influences on chronic fatigue. Results: The concordance rate was higher in monozygotic than dizygotic twins for each definition of chronic fatigue. For idiopathic chronic fatigue, the concordance rates were $55 \%$ in monozygotic and $19 \%$ in dizygotic twins $(p=.042)$. The estimated heritability in liability was $19 \%(95 \%$ confidence interval $=0-56)$ for chronic fatigue $\geq 6$ months, $30 \%(95 \%$ confidence interval $=0-81)$ for chronic fatigue not explained by medical conditions, and $51 \%(95 \%$ confidence interval $=7-96$ ) for idiopathic chronic fatigue. Conclusions: These results provide evidence supporting the familial aggregation of fatigue and suggest that genes may play a role in the etiology of chronic fatigue syndrome. Key words: chronic fatigue, twins, concordance, genetics.

$\mathrm{CDC}=$ Centers for Disease Control and Prevention; CFS = chronic fatigue syndrome; $\mathrm{CI}=$ confidence interval; DIS = Diagnostic Interview Schedule; DZ = dizygotic; HLA = human leukocyte antigen; $\mathrm{MZ}=$ monozygotic.

\section{INTRODUCTION}

Fatigue is a common complaint in primary care settings (1-5), being reported by at least $20 \%$ of patients seeking care. Likewise, large community surveys indicate that up to half of the general population experiences fatigue, usually of limited duration (6-8). In most cases the fatigue is transient, explained by prevailing circumstances, relieved by rest, and of little cause for concern. In both community and clinical settings, fatigue is typically more frequent among women than men. However, persistent and debilitating fatigue is the hallmark of chronic fatigue syndrome (CFS), an illness characterized by disabling fatigue associated with muscle pain, pharyngitis, and alterations in mood, sleep, and neurocognition (9).

From the Departments of Medicine (D.B., S.A., M.B.) and Psychiatry and Behavioral Sciences (K.S.), University of Washington, Seattle, WA; the Division of Epidemiology-Biostatistics (J.G., R.H.), University of Illinois, Chicago, IL; and the Virginia Institute for Psychiatric and Behavioral Genetics (P.S., M.N.), Virginia Commonwealth University, Richmond, VA.

Address reprint requests to: Dedra Buchwald, MD, Harborview Medical Center, 325 9th Ave., Box 359780, Seattle, WA 98104. Email: dedra@u.washington.edu

Received for publication May 22, 2000; revision received April 9, 2001.
Many theories on the pathophysiology of CFS have been proposed (10). Initially the prominence of infectious, neurocognitive, and psychological symptoms suggested a viral illness or psychiatric disorder (11, 12). Subsequently a variety of findings related to sleep pathology and neuroendocrine, immunological, and autonomic dysfunction were observed in subgroups of patients with CFS (13-16). At the same time, our group (anecdotal observations) and others (17) have noted that CFS and other unexplained chronically fatiguing conditions often affect several members of the same family.

Twin studies have been useful in elucidating the relative contributions of genetic and environmental factors to numerous medical and psychiatric disorders, and they are especially helpful for the study of diseases of unknown cause (18). Recently investigators demonstrated a genetic influence on an index of general fatigue in a sample of Australian twins (19). With this in mind, we undertook a classical twin study to investigate the possible genetic and nongenetic influences on CFS. In this study we examined the familial clustering of fatigue by comparing concordance rates in monozygotic (MZ) and dizygotic (DZ) female-female twins for three definitions of fatigue and developed initial estimates of the heritability of chronic fatigue.

\section{METHODS}

\section{Identification of Twins and Data Collection}

Twins were recruited through a variety of sources, including advertisements in patient support group newsletters (63\%), clinicians and researchers familiar with CFS (12\%), solicitations placed on CFS electronic bulletin boards (8\%), twin researchers or organizations $(5 \%)$, friends and relatives $(3 \%)$, and various other means (9\%). All recruitment efforts emphasized that fatigued twins were 
desired regardless of either the health of their co-twin or a definitive diagnosis of CFS. Of the 204 pairs identified, complete data were available for both members of 176 pairs (87\%). Among these, 146 pairs were female-female, 10 were male-male, and 20 were malefemale twins. This study was restricted to female-female twins because the samples of male-male and male-female twins were too limited to analyze. Written, informed consent was obtained from each subject in accordance with the regulations of our institutional Human Subjects Office.

All study subjects completed an extensive mailed survey questionnaire that included questions on fatigue and the CFS symptom criteria according to the 1994 revised Centers for Disease Control and Prevention (CDC) research definition (9). For nonfatigued twins, a control version of questions was used that did not reference fatigue. A trained research assistant administered the Diagnostic Interview Schedule (DIS), version III-A (20), by telephone to all twin pairs in which at least one member reported fatigue of $\geq 6$ months in duration. The DIS assigns diagnoses using a computer algorithm based on criteria of the Diagnostic and Statistical Manual of Mental Disorders, third edition revised (21). The interview included the sections on major depression, dysthymia, generalized anxiety, panic, agoraphobia, posttraumatic stress disorder, mania, bipolar disorders, schizophrenia, eating disorders, somatization, and substance abuse/dependence. Depression with melancholic features was scored without including symptoms attributable to CFS.

The questionnaire also included a checklist of self-reported medical problems; twins indicated whether a condition was currently active or had resolved and whether it had been evaluated by a physician. The application of the CDC-defined exclusionary medical conditions to the checklist was determined by consensus of two general internists, a psychiatrist with expertise in CFS, an infectious disease specialist, and an internist/emergency room physician with knowledge of, but little exposure to, patients with CFS. Examples from the comprehensive list of exclusionary disorders included (but was not limited to) steroid-dependent asthma, infectious hepatitis, diabetes, cancer (other than skin cancer), congestive heart failure, stroke, cirrhosis, multiple sclerosis, and systemic lupus erythematosus. To assess the performance of our list of exclusionary conditions, subjects' self-reported health conditions were compared with physician confirmation of these diagnoses by means of chart review and telephone contact with treating physicians for a subsample of twins. Among 40 twins, we did not find any fatigued participant to be ineligible due to an exclusionary condition that was missing or inaccurately reported on the checklist. Conversely, no exclusionary conditions were observed in any twin who self-reported good health.

\section{Definition of Fatigue}

We defined three progressively more stringent (but not mutually exclusive) case definitions of fatigue. The first definition, chronic fatigue, was based on the response to a single question: "Have you been fatigued for at least 6 months?" No further inclusionary or exclusionary conditions were applied.

The second definition, chronic fatigue not explained by medical exclusions, classified all twins according to chronic fatigue using data obtained solely from the mailed questionnaire. An algorithm that defined chronic fatigue using the medical exclusionary components of the CDC case definition for CFS was developed (9). The exclusionary medical criteria were applied to both the chronically fatigued and nonfatigued twins. To be classified as having medically unexplained chronic fatigue, twins were required to report fatigue of $\geq 6$ months duration that was not lifelong and that resulted in a substantial reduction of occupational, educational, social, or per- sonal activities. Twins were excluded from this definition of chronic fatigue if they had a body mass index $>45$ (as stipulated in the CDC criteria) or reported any of the exclusionary medical conditions.

The third definition (idiopathic chronic fatigue or chronic fatigue not explained by medical and psychiatric exclusions) further restricted our sample on the basis of DIS-generated psychiatric diagnoses considered exclusionary by the CDC case definition (9). These included lifetime mania, hypomania, bipolar disorder, schizophrenia, major depression with psychotic or melancholic features, anorexia or bulimia nervosa, and current alcohol or substance abuse/ dependence. Identical psychiatric exclusionary criteria were used with both fatigued and nonfatigued twins.

\section{Determination of Zygosity}

Studies have shown that questions about childhood similarity in twin pairs can be used to correctly classify zygosity with an accuracy of $95 \%$ to $98 \%$ compared with biological indicators $(22,23)$. As part of the mailed questionnaire all twins were asked questions about childhood similarity. Initial classification of twin pairs was based on concordant responses to the following question: "When you were young, were you as alike as peas in a pod?" Twins were classified as MZ if they both answered affirmatively; those pairs in which both twins denied this degree of similarity were considered to be DZ. Further refinement and classification of twin pairs was based on additional childhood similarity indicators (eg, eye and hair color and general physical characteristics). Full details of our zygosity classification algorithm can be found elsewhere (24).

\section{Statistical Analysis}

Two measures of twin concordance were calculated as descriptive indices of the familial clustering of fatigue. The pairwise concordance rate gives the percentage of affected pairs that are concordant (ie, both members of the pair meet the definition for chronic fatigue); it is simply defined as the ratio of fatigue-concordant twins divided by the sum of the number of fatigue-discordant and fatigueconcordant twins. The proband concordance rate gives an estimate of the prevalence of fatigue among twin siblings of probands. Concordance rates and associated 95\% exact confidence intervals are presented separately for each of the three definitions of fatigue $(\geq 6$ months of fatigue, chronic fatigue not attributable to medical exclusion criteria, and idiopathic chronic fatigue not explained by medical or psychiatric exclusion criteria). The two-tailed Fisher's exact test was used for hypothesis testing to examine whether the difference between concordance rates in MZ and DZ pairs was significant for each of the three definitions of chronic fatigue. When MZ rates were higher than DZ rates, this was interpreted as evidence for a genetic influence on chronic fatigue.

We also conducted a separate statistical analysis comparing the concordance rates for the most stringent definition of idiopathic chronic fatigue after further excluding all twins with a lifetime history of major depression on the structured psychiatric interview. Although this is not part of the formal CDC case definition for CFS, we were concerned that any differences in concordance rates for idiopathic chronic fatigue might be the result of comorbid depression, which is known to have a genetic component (25).

Estimates of the relative contribution of genetic and nongenetic sources of phenotypic variability for each definition of chronic fatigue are derived using a multifactorial model of inheritance that assumes both polygenetic and environmental effects (26). The number of concordant and discordant pairs, in combination with external estimates of the population prevalence for the three different definitions of chronic fatigue, were used to derive estimates of the 
relative proportion of variance in liability for chronic fatigue attributable to additive genetic (commonly referred to as heritability), common environment, and unique environment. Prevalence estimates of chronic fatigue in females were obtained from a recently completed population-based study of CFS (L. Jason, personal communication, 1998); these prevalences were $4.2 \%, 2.1 \%$, and $0.4 \%$ for each of our three increasingly stringent definitions of chronic fatigue. The mean age of the female chronic fatigue cases in the population-based study was very similar to the average age in the twin sample (44 vs. 46 years). The structural equation modeling program Mx (27) was used to derive the estimates of additive genetic $\left(a^{2}\right)$, common environment $\left(c^{2}\right)$, and unique environment $\left(e^{2}\right)$ effect as well as the associated $95 \%$ confidence intervals (28).

Because this was a self-selected sample of twins, we attempted to account for possible ascertainment biases that could influence our estimates of genetic and nongenetic effects (29). We conducted a series of alternative structural equation models based on varying the ratio of the probability of ascertaining fatigue-concordant versus fatigue-discordant twin pairs. When this ratio was 1 , there was no differential ascertainment. An ascertainment correction ratio of 2 implies that a fatigued twin with a fatigued co-twin is twice as likely to be ascertained as a fatigued twin with a healthy co-twin. Different models were estimated with ascertainment correction factors that ranged from 1 to a maximum value of 4 .

\section{RESULTS}

Table 1 presents the concordance rates in MZ and DZ twins according to the three increasingly stringent definitions of chronic fatigue. The concordance rates for chronic fatigue of $\geq 6$ months duration were greater in MZ twins than DZ twins, although this difference was not statistically significant $(p=.253)$. A similar pattern of higher MZ than DZ concordance rates was observed for chronic fatigue not attributable to the medical exclusion criteria; this difference was also not significant $(p=.109)$. For idiopathic chronic fatigue not explained by the medical or psychiatric exclusion criteria, the difference in concordance rates became larger, with the MZ pairwise (38\%) and proband (55\%) concordance rates significantly elevated $(p=.042)$ compared with the respective DZ rates (11\% pairwise and $19 \%$ proband). To explore whether depression could be confounding our analyses, we reanalyzed chronic fatigue not explained by the medical or psychiatric exclusion criteria after excluding twins if either had a history of major depression. In this highly refined sample of $25 \mathrm{MZ}$ and $11 \mathrm{DZ}$ twins, the difference in concordance rates remained statistically significant ( $p=.016$ ) with a $40 \%$ pairwise and $57 \%$ proband rate in the MZ twins and a pairwise and proband rate of $0 \%$ in the DZ twins.

Figure 1 presents estimates of the relative contribution of genetic and nongenetic effects for the three definitions of chronic fatigue. For chronic fatigue of $\geq 6$ months, genetic effects were relatively modest, accounting for $19 \%$ of the variance ( $95 \%$ CI $=0-56$ ), whereas common environmental effects accounted for $69 \%$ of the variance $(95 \% \mathrm{CI}=32-89)$. For chronic fatigue not explained by medical conditions, common environmental effects still predominated $\left(a^{2}=30 \%\right.$, $95 \%$ CI $=0-81 ; c^{2}=58 \%, 95 \%$ CI $\left.=9-89\right)$. Idiopathic chronic fatigue not explained by medical or psychiatric exclusionary criteria displayed the largest genetic influence with a heritability of $51 \%(95 \% \mathrm{CI}=$ 7-96). As shown in Table 2, adjusting for various levels of differential ascertainment of concordant to discordant pairs yielded results that were generally con-

TABLE 1. Concordance for Chronic Fatigue in Monozygotic and Dizygotic Female Twin Pairs

\begin{tabular}{|c|c|c|c|}
\hline Zygosity & Fatigue $\geq 6$ months $^{a}$ & $\begin{array}{c}\text { Chronic Fatigue Not } \\
\text { Due to Medical } \\
\text { Exclusions }^{b}\end{array}$ & $\begin{array}{c}\text { Chronic Fatigue Not } \\
\text { Due to Medical or } \\
\text { Psychiatric } \\
\text { Exclusions }^{c}\end{array}$ \\
\hline Monozygotic, $N$ of pairs & 106 & 77 & 55 \\
\hline Concordant, $\mathrm{N}$ of pairs & 44 & 30 & 21 \\
\hline Discordant, $N$ of pairs & 62 & 47 & 34 \\
\hline Pairwise concordance \% & 42 & 39 & 38 \\
\hline $95 \% \mathrm{Cl}$ & $32-52$ & $28-51$ & $25-52$ \\
\hline Proband concordance \% & 59 & 56 & 55 \\
\hline $95 \% \mathrm{Cl}$ & $50-67$ & $46-66$ & $43-67$ \\
\hline Dizygotic, $N$ of pairs & 40 & 28 & 19 \\
\hline Concordant, $N$ of pairs & 12 & 6 & 2 \\
\hline Discordant, $N$ of pairs & 28 & 22 & 17 \\
\hline Pairwise concordance \% & 30 & 21 & 11 \\
\hline $95 \% \mathrm{Cl}$ & $17-47$ & $8-41$ & $1-33$ \\
\hline Proband concordance \% & 46 & 35 & 19 \\
\hline $95 \% \mathrm{Cl}$ & $32-61$ & $20-54$ & $5-42$ \\
\hline
\end{tabular}

${ }^{a} p=.253$ by Fisher's exact test for comparing the MZ and DZ concordances rates.

${ }^{b} p=.109$ by Fisher's exact test for comparing the MZ and DZ concordances rates.

${ }^{c} p=.042$ by Fisher's exact test for comparing the MZ and DZ concordances rates. 


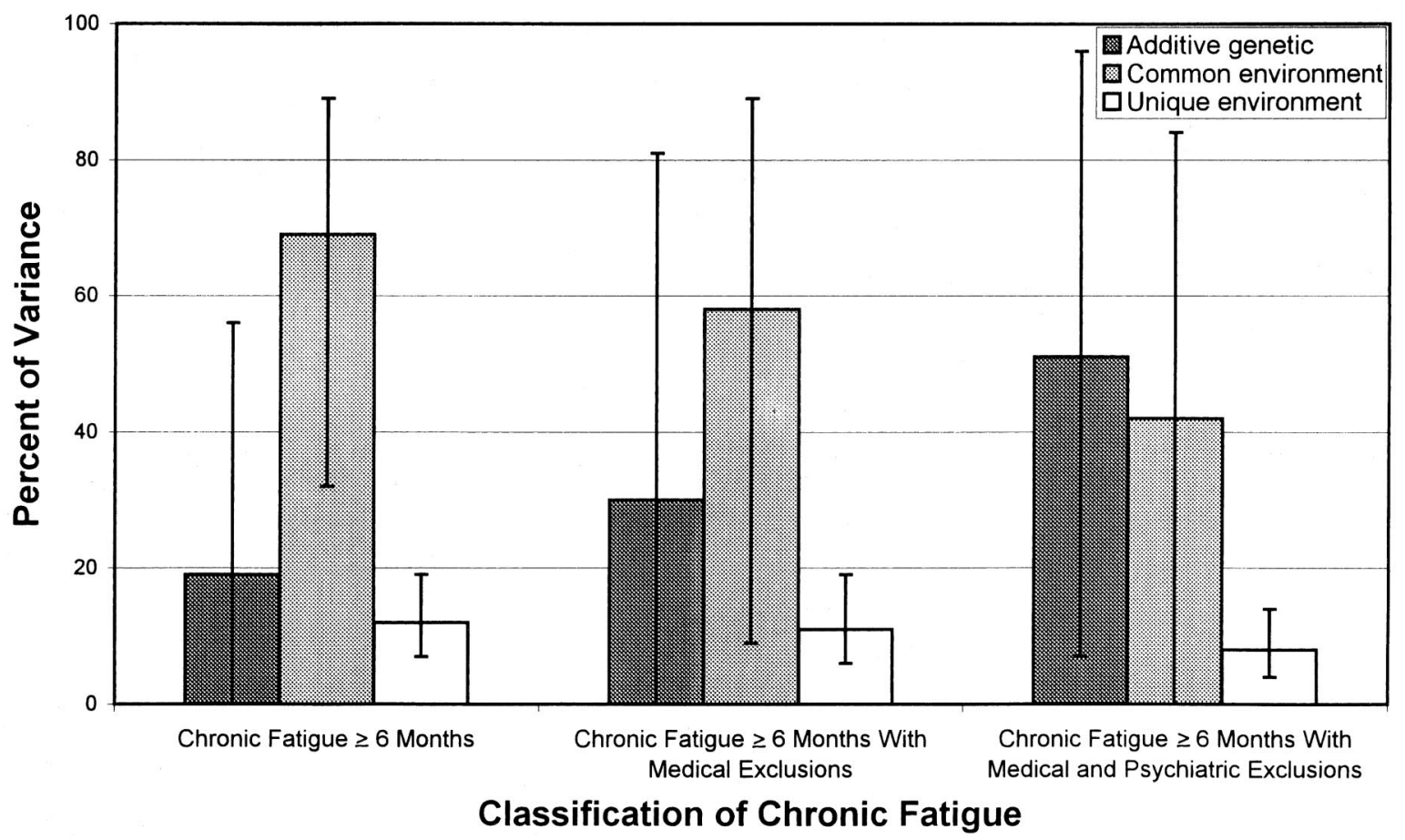

Fig. 1. Estimates of genetic and environmental influence on the liability to chronic fatigue with $95 \%$ confidence intervals.

TABLE 2. Estimates of the Percentage of Variance in Liability to Chronic Fatigue Due to Additive Genetics, Common Environment, and Unique Environment Under Different Twin Ascertainment Assumptions

\begin{tabular}{|c|c|c|c|c|c|c|c|c|c|}
\hline \multirow[t]{2}{*}{$\begin{array}{c}\text { Assumed } \\
\text { Ascertainment Ratio }^{a}\end{array}$} & \multicolumn{3}{|c|}{ Fatigue $\geq 6$ months } & \multicolumn{3}{|c|}{$\begin{array}{l}\text { Chronic Fatigue Not Due to } \\
\text { Medical Exclusions }{ }^{b}\end{array}$} & \multicolumn{3}{|c|}{$\begin{array}{c}\text { Chronic Fatigue Not Due to } \\
\text { Medical or Psychiatric } \\
\text { Exclusions }\end{array}$} \\
\hline & $a^{2}$ & $c^{2}$ & $e^{2}$ & $a^{2}$ & $c^{2}$ & $e^{2}$ & $a^{2}$ & $c^{2}$ & $e^{2}$ \\
\hline 1.0 & 19 & 69 & 12 & 30 & 58 & 11 & 51 & 42 & 8 \\
\hline 1.5 & 24 & 57 & 19 & 37 & 48 & 17 & 58 & 30 & 12 \\
\hline 2.0 & 26 & 48 & 26 & 40 & 37 & 23 & 61 & 22 & 16 \\
\hline 2.5 & 28 & 40 & 31 & 42 & 30 & 28 & 63 & 17 & 20 \\
\hline 3.0 & 29 & 35 & 36 & 43 & 25 & 32 & 64 & 13 & 23 \\
\hline 3.5 & 29 & 30 & 41 & 42 & 21 & 36 & 65 & 10 & 25 \\
\hline 4.0 & 30 & 26 & 45 & 43 & 18 & 39 & 65 & 7 & 28 \\
\hline
\end{tabular}

${ }^{a}$ The ratio is defined as of the probability of ascertaining fatigue-concordant versus fatigue-discordant twin pairs. When the ratio $=1$, it is assumed that there is no differential ascertainment of concordant compared with discordant pairs. Ratios $>1$ suggest that fatigue-concordant twins are more likely than fatigue-discordant twins to be identified in the Chronic Fatigue Twin Registry.

${ }^{b}$ Includes five individuals excluded for a body mass index $>45$.

sistent. For chronic fatigue of $\geq 6$ months, the estimates of genetic effects ranged from $19 \%$ with no ascertainment adjustment to a maximum of $30 \%$ with an ascertainment correction ratio of 4 ; likewise, for chronic fatigue not explained by medical conditions, genetic effects ranged from $30 \%$ to $43 \%$. Common environmental effects, which were substantial for both fatigue of $\geq 6$ months and chronic fatigue not explained by medical conditions, were reduced as the ascertainment correction ratio was increased. For chronic fatigue not explained by medical or psychiat- ric exclusionary criteria, the genetic effects increased from $51 \%$ to $65 \%$ as the ascertainment ratio increased from 1 to 4 , whereas the common environmental influence was diminished from $42 \%$ to $7 \%$.

\section{DISCUSSION}

At the beginning of the century a popular diagnosis that bears some resemblance to modern-day CFS was neurasthenia. At the time most authorities on neurasthenia favored a distinction between an inherited and 
an acquired form (30). Moreover, it was commonly observed that the illness ran in families and could begin in early life (30). Although a greater appreciation of the methodological difficulties in separating congenital and acquired factors developed, a role of heritability was never eliminated; instead it became unfashionable to ascribe neurasthenia to inherited factors. Only in the context of "effort syndrome," a condition of easy fatigability with exertion, were careful studies performed; these studies showed a modest genetic contribution (31). No further studies were conducted for several decades on the heritability of fatiguing disorders.

Modern genetic technologies unavailable to the previous generation of neurasthenia researchers are now accessible, but few investigators have applied these to CFS. In one of the first reports, a Scottish group attempted to determine HLA status in patients with CFS but were inexplicably hampered by difficulties in obtaining lymphocyte expression of HLA markers (32). Another investigator, who did not experience technical problems, reported no specific association of HLA class II antigens (33). In contrast, American researchers found that HLA-DQ3 and HLA-DR5 antigens were significantly associated with CFS (34). Taken together, these and other studies of HLA type have produced conflicting results and have failed to show any consistent association with CFS $(11,35)$.

Several other investigations have suggested that a combination of host and environmental factors may be involved in the etiology of CFS. One report identified a family in which 5 of 6 siblings and 3 other immediate family members developed CFS as adults (17). Blood samples were collected and tested for natural killer cell activity over a 2-year period from the 8 affected and 12 unaffected family members and 8 normal control subjects. The cytotoxic activity of the affected immediate family members was significantly lower than that of the control subjects, with unaffected family members intermediate between these two groups. Although a familial influence (ie, common environment) could also explain their findings, the authors concluded that the natural killer cell dysfunction in this family may have resulted from a genetically determined immunological abnormality predisposing to CFS. Others have recently described a new pattern of autoantibodies to gangliosides, phospholipids, and especially serotonin in CFS patients (36). The observation that these antibodies were present among family members of CFS patients was interpreted in favor of an inherited predisposition to the illness. Finally, in a community-wide investigation of pediatric cases of a CFS-like illness, the best predictive model of illness produced significant estimates of relative risk for both environmental and genetic/familial effects, including a risk of 23.3 for symptoms among other family members (37).

Twin studies have been widely used to estimate the heritability of numerous complex disorders and conditions. Recent research has estimated that heritable influence accounts for $39 \%$ of the variation in major depression (38), 54\% in osteoarthritis (39), and $44 \%$ in blood pressure in the elderly (40). However, twin and family studies have not been extensively used to examine the heritability of CFS and similar chronically fatiguing conditions. An exhaustive, computerized search of the medical literature of the last decade yielded only four citations on twins and fatigue, all using a large volunteer registry of Australian twins (19, 41-43). These publications examined shorter periods of fatigue (eg, 1 week to 1 month) and not CFS-like illnesses $(19,41-43)$ among children and adolescents as reported by their parents (41) and older individuals (43). Interestingly, several of these studies found that the genetic and environmental influences on fatigue were for the most part independent of those for anxiety, depression, and psychological distress $(19,42,43)$. Despite different populations and highly variable case definitions of fatigue, these investigations, like our own, found evidence to support a familial effect.

Publications on objective measures of energy metabolism have also demonstrated that many characteristics that contribute to aerobic capacity are heritable (44-49). For example, level of habitual physical activity, resting metabolic rate, energy cost of exercise, endurance performance response to training, and maximum oxygen consumption $\left(\mathrm{VO}_{2 \max }\right)$ are all, to some extent, genotype-dependent $(45,47)$. In this regard, an intriguing recent report claims to have identified a gene for physical performance (50). Finally, the awareness of symptoms depends, in large part, on how the central nervous system processes information (ie, an individual's perception). Because MZ twins have remarkably similar cortical structures, electroencephalographic patterns, neurotransmitter activity, and autonomic nervous system activation symptom perception clearly could have a heritable basis (51).

This study has several potential limitations. First, as with all classical twin studies, there is the assumption that the rearing experience of $\mathrm{MZ}$ and $\mathrm{DZ}$ twins is comparable. If this so-called equal environment assumption is violated, the estimates of genetic influence could be falsely inflated. However, this assumption has recently been examined for several psychiatric disorders and found to be quite tenable $(52,53)$. Second, it is important to acknowledge that the method we used to identify the twin sample was not ideal. We used a selected sample of volunteer 
twins who responded to solicitations from a variety of sources. This approach was a practical solution to identifying a relatively large sample of twins with chronic fatigue. The more desirable strategy of systematically identifying twins with chronic fatigue and CFS from a well-defined, truly population-based twin registry is not readily accomplished. The use of selected samples of twins has a long history in twin studies of medical and psychiatric disorders (18) and has recently been applied successfully in a study of the genetics of homosexuality (28). However, this approach could result in potentially biased ascertainment. Although we repeatedly emphasized in all advertisements and contacts with support groups and physicians that probands could participate regardless of either a definitive diagnosis or the health of their co-twin, it is likely that subjects screened themselves as eligible or ineligible. In this study, an ascertainment bias could have occurred if twin pairs in which both members experienced fatigue were more likely to volunteer and complete the lengthy booklet. We addressed this in our analysis by constructing a series of ascertainment scenarios to examine the impact on heritability estimates. Another type of ascertainment bias might have occurred if there was differential participation of chronic fatigue-concordant pairs according to zygosity. If an excess of MZ concordant twins had volunteered, this could have resulted in an overestimate of the influence of genetics. Without a population-based sample of twins, it is very difficult to estimate the extent of this type of bias.

Other possible limitations are the methods we used to define and measure fatigue and exclusionary medical conditions. Although a clinical examination of all twins was not feasible, we closely followed the CFS symptom and psychiatric criteria as articulated by the CDC. In addition, our three increasingly stringent measures of fatigue were consistent with those used in several recent epidemiological studies (L. Jason, L Steele, S. Reyes, personal communication, 1998) and permitted us to assess the magnitude of genetic influence across these different definitions. We were likewise concerned with the use of self-reported health conditions. This methodology could result in either an overestimate or underestimate of the actual rate of idiopathic chronic fatigue depending on whether individuals did not report conditions that might be exclusionary or incorrectly claimed to have been diagnosed with conditions they did not actually have. However, we presented evidence that the measurement of exclusionary medical conditions using selfreport was adequate. Lastly, we considered the possibility that the heritable effects on fatigue might be a surrogate for a genetic influence on major depression, because this diagnosis is common in chronic fatigue (54), has known genetic influences (25), and is not an exclusionary psychiatric criterion for CFS. When we excluded all twins with a lifetime history of major depression from the definition of idiopathic chronic fatigue, the $M Z$ concordance rates remained higher than the DZ rates. Similarly, researchers using the Australian Twin Registry have demonstrated that fatigue seems to be under genetic influence that is distinct from the genetic influence on depression (19, 42, 43).

In conclusion, the present study supports the familial aggregation of fatiguing illnesses. Furthermore, these data are consistent with the presence of a genetic influence on idiopathic chronic fatigue. An important observation was that heritability increased as our definition of chronic fatigue was made more stringent. This suggests that future research would benefit by distinguishing CFS from milder forms of chronic fatigue. Our study provides evidence that there is a genetic vulnerability to idiopathic chronic fatigue. In this respect, CFS and related conditions may be similar to other disorders in which situational and environmental factors enhance the likelihood of illness expression. A practical implication for the non-ill proband will be to examine which of these factors might be important triggers and perpetuators of CFS and to identify those that might be amenable to change.

The authors thank the participants in the University of Washington Twin Registry for their cooperation, patience, and goodwill, and Dr. Leigh Sawyer, Program Officer, National Institute of Allergy and Infectious Diseases, for her encouragement and support. We also acknowledge Anthony Komaroff and Seth Eisen for their insightful comments on this manuscript and our advisory panel, who with sage advice and ongoing encouragement improved our scientific efforts. This work was funded by Grant U19 AI38429 from the National Institutes of Health (D.B.).

\section{REFERENCES}

1. Bates DW, Schmitt W, Buchwald D, Ware NC, Lee J, Thoyer E, Kornish RJ, Komaroff AL. Prevalence of fatigue and chronic fatigue syndrome in a primary care practice. Arch Intern Med 1993;153:2759-65.

2. Buchwald D, Sullivan J, Komaroff A. Frequency of "chronic active Epstein-Barr virus infection" in a general medical practice. JAMA 1987;257:2303-7.

3. Cathebras PJ, Robbins JM, Kirmayer LJ, Hayton BC. Fatigue in primary care: prevalence, psychiatric comorbidity, illness behavior, and outcome. J Gen Intern Med 1992;7:276-86.

4. Kroenke K, Wood DR, Mangelsdorff AD, Meier NJ, Powell JB. Chronic fatigue in primary care: prevalence, patient characteristics, and outcome. JAMA 1988;260:929-34. 


\section{BUCHWALD et al.}

5. McDonald E, David AS, Pelosi AJ, Mann AH. Chronic fatigue in primary care attenders. Psychol Med 1993;23:987-98.

6. Pawlikowska T, Chalder T, Hirsch SR, Wallace P, Wright DJ, Wessely SC. Population based study of fatigue and psychological distress. BMJ 1994;308:763-6.

7. Chen M. The epidemiology of self-perceived fatigue among adults. Prev Med 1986;15:74-81.

8. Hammond E. Some preliminary findings on physical complaints from a prospective survey of 1,064,004 men and women. Am J Public Health 1964;54:11-23.

9. Fukuda K, Straus SE, Hickie I, Sharpe MC, Dobbins JG, Komaroff A. The chronic fatigue syndrome: a comprehensive approach to its definition and study. Ann Intern Med 1994;121:953-9.

10. Komaroff AL, Buchwald DS. Chronic fatigue syndrome: an update. In: Coggins CH, Hancock EW, Levitt LJ, editors. Annual review of medicine. Vol 49. Palo Alto (CA): Annual Reviews; 1998. p. 1-13.

11. Straus SE, Tosato G, Armstrong G, Lawley T, Preble OT, Henle W, Davey R, Pearson G, Epstein J, Brus I. Persisting illness and fatigue in adults with evidence of Epstein-Barr virus infections. Ann Intern Med 1985;107:7-16.

12. Manu P, Matthews DA, Lane TJ, Tennen H, Hesselbrock V, Mendola R, Affleck G. The mental health of patients with a chief complaint of chronic fatigue: a prospective evaluation and follow-up. Arch Intern Med 1988;148:2213-7.

13. Buchwald D, Pascualy R, Bombardier C, Kith P. Sleep disorders in patients with chronic fatigue. Clin Infect Dis 1994;18(Suppl 1):S68-72.

14. Demitrack MA, Dale JK, Straus SE, Laue L, Listwak SJ, Kruesi MJ, Chrousos GP, Gold PW. Evidence for impaired activation of the hypothalamic-pituitary-adrenal axis in patients with chronic fatigue syndrome. J Clin Endocrinol Metab 1991;73: 1224-34.

15. Landay AL, Jessop C, Lennette ET, Levy JA. Chronic fatigue syndrome: clinical condition associated with immune activation. Lancet 1991;338:707-12.

16. Bou-Holaigah I, Rowe PC, Kan J, Calkins H. The relationship between neurally mediated hypotension and the chronic fatigue syndrome. JAMA 1995;274:961-7.

17. Levine PH, Whiteside TL, Friberg D, Bryant J, Colclough G, Herberman RB. Dysfunction of natural killer activity in a family with chronic fatigue syndrome. Clin Immunol Immunopathol 1998;88:96-104.

18. Hubric Z, Robinette CD. The study of human twins in medical research. N Engl J Med 1984;310:435-41.

19. Hickie I, Kirk K, Martin N. Unique genetic and environmental determinants of prolonged fatigue: a twin study. Psychol Med 1999;29:259-68.

20. Robins LN, Helzer JE. Diagnostic Interview Schedule (DIS): version III-A. St Louis: Department of Psychiatry, Washington University School of Medicine; 1985.

21. DSM-III-R. Diagnostic and statistical manual of mental disorders. 3rd ed revised. Washington DC: American Psychiatric Association; 1987.

22. Torgersen S. The determination of twin zygosity by means of a mailed questionnaire. Acta Genet Med Gemellol (Roma) 1979; 28:225-36.

23. Eisen SA, Neuman R, Goldberg J, Rice J, True W. Determining zygosity in the Vietnam Era Twin Registry: an approach using questionnaires. Clin Genet 1989;35:423-32.

24. Buchwald D, Herrell R, Ashton S, Belcourt M, Schmaling K, Goldberg J. Chronic fatigue twin registry: method of construction, composition, and zygosity assignment. Twin Res 1999;2: 203-11.
25. Kendler KS, Heath A, Martin NG, Eaves LJ. Symptoms of anxiety and depression in a volunteer twin population: the etiologic role of genetic and environmental factors. Arch Gen Psychiatry 1986; 43:213-21.

26. Khoury MJ, Beaty TH, Cohen BH. Fundamentals of genetic epidemiology. New York: Oxford University Press; 1993.

27. Neale MC. Mx: statistical modeling. 2nd ed. Richmond (VA): Department of Psychiatry, Medical College of Virginia; 1997.

28. Neale MC, Miller MB. The use of likelihood-based confidence intervals in genetic models. Behav Genet 1997;27:113-20.

29. Bailey JM, Pillard RC, Neale MC, Agyei Y. Heritable factors influence sexual orientation in women. Arch Gen Psychiatry 1993;50:217-23.

30. Wessely S, Hotopf M, Sharpe M. Chronic fatigue syndromes. New York: Oxford University Press; 1997.

31. Wheeler E, White P, Reed E, Cohon M. Familial incidence of neurocirculatory asthenia ('anxiety neurosis,' 'effort syndrome'). J Clin Invest 1948;27:562-82.

32. Behan PO, Bakheit AM. Clinical spectrum of post-viral fatigue syndrome. Br Med Bull 1991;47:793-808.

33. Middleton D, Savage D, Smith D. No association of HLA class II antigens in chronic fatigue syndrome. Dis Markers 1991;9:47-9.

34. Keller RH, Lane JL, Klimas N, Reiter WM, Fletcher MA, van Riel F, Morgan R. Association of HLA class II antigens and chronic fatigue immune dysfunction syndrome. Clin Infect Dis 1994;18: S154-6.

35. Marrie TJ, Ross L, Montague TJ, Doan B. Post-viral fatigue syndrome. Clin Ecol 1987;5:5-10.

36. Klein R, Berg PA. High incidence of antibodies to 5-hydroxytryptamine, gangliosides and phospholipids in patients with chronic fatigue and fibromyalgia syndrome and their relatives: evidence for a clinical entity of both disorders. Eur J Med Res 1995;1:21-6.

37. Bell KM, Cookfair D, Bell DS, Reese P, Cooper L. Risk factors associated with chronic fatigue syndrome in a cluster of pediatric cases. Rev Infect Dis 1991;13(Suppl 1):S32-8.

38. Kendler KS, Prescott CA. A population-based study of lifetime major depression in men and women. Arch Gen Psychiatry 1999;56:39-44.

39. Spector TD, Cicuttini F, Baker J, Loughlin J, Hart D. Genetic influence on osteoarthritis. BMJ 1996;312:940-3.

40. Hong Y, de Faire U, Heller DA, McClearn GE, Pedersen N. Genetic and environmental influences on blood pressure in elderly twins. Hypertension 1994;24:663-70.

41. Farmer A, Scourfield J, Martin N, Cardno A, McGuffin P. Is disabling fatigue in childhood influenced by genes? Psychol Med 1999;29:279-82.

42. Hickie I, Bennett B, Lloyd A, Heath A, Martin N. Complex genetic and environmental relationships between psychological distress, fatigue and immune functioning: a twin study. Psychol Med 1999;29:269-77.

43. Kirk KM, Hickie IB, Martin NG. Fatigue as related to anxiety and depression in a community-based sample of twins aged over 50. Soc Psychiatry Epidemiol 1999;34:85-90.

44. Bouchard C, Dionne FT, Simoneau JA, Boulay MR. Genetics of aerobic and anaerobic performances. Exerc Sport Sci Rev 1992; 20:27-58.

45. Bouchard C, Lesage R, Lortie G, Simoneau JA, Hamel P, Boulay MR, Perusse L, Theriault G, Leblanc C. Aerobic performance in brothers, dizygotic and monozygotic twins. Med Sci Sports Exerc 1986;18:639-46.

46. Fagard R, Bielen E, Amery A. Heritability of aerobic power and anaerobic energy generation during exercise. J Appl Physiol 1991;70:357-62. 
47. Hamel P, Simoneau JA, Lortie G, Boulay MR, Bouchard C. Heredity and muscle adaptation to endurance training. Med Sci Sports Exerc 1986;18:690-9.

48. Simoneau JA, Bouchard C. Genetic determinism of fiber type proportion in human skeletal muscle. FASEB J 1995;9: 1091-5.

49. Tremblay A, Poehlman ET, Despres JP, Theriault G, Danforth E, Bouchard C. Endurance training with constant energy intake in identical twins: changes over time in energy expenditure and related hormones. Metabolism 1997;46:499-503.

50. Montgomery HE, Marshall R, Hemingway H, Myerson S, Clarkson P, Dollery C, Hayward M, Holliman DE, Jubb M, World M, Thomas EL, Brynes AE, Saeed N, Barnard M, Bell JD, Prasad K, Rayson M, Talmud PJ, Humphries SE. Human gene for physical performance. Nature 1998;393:221-2.
51. Watson D, Pennebaker JW. Situational, dispositional, and genetic bases of symptom reporting. In: Skelton JA, Croyle RT, editors. Mental representation in health and illness. New York: Springer Verlag; 1991. p. 61-84.

52. Hettema JM, Neale MC, Kendler KS. Physical similarity and the equal-environment assumption in twin studies of psychiatric disorders. Behav Genet 1995;25:327-35.

53. Kendler KS, Gardner CO. Twin studies of adult psychiatric and substance dependence disorders: are they biased by differences in the environmental experiences of monozygotic and dizygotic twins in childhood and adolescence? Psychol Med 1998;28: 625-33.

54. Manu P, Matthews DA, Lane TJ. The mental health of patients with a chief complaint of chronic fatigue: a prospective evaluation and follow-up. Arch Intern Med 1988;148:2213-7. 